\title{
Trends in cloud cover from 1960 to 2005 over South Africa
}

\author{
AC Kruger* \\ South African Weather Service, Private Bag X097, Pretoria 0001, South Africa
}

\begin{abstract}
Seasonal trends in low and total cloud cover, as well as for associated climate variables diurnal temperature range (DTR) and number of rain days, are investigated for South Africa. It is also investigated whether the observed trends and variability in cloud cover could be related to the El Niño-Southern Oscillation (ENSO) phenomenon, which has a major influence on the variability of summer rainfall in South Africa. These trends have not been investigated recently and in such detail. In the light of the climate change debate, updated studies of historical climate change are important, especially for regions and climate variables of which such studies are not published often. Seasonal trends of daily means were examined from quality-controlled data time series of 28 climate stations over South Africa, for the period 1960 to 2005. Regional trends could be determined by averaging series of stations showing similar trends, within areas delineated in such a way that the trend of the averaged series would be statistically significant. In this way the intra-seasonal spatial variability of same trend regions, as well as the spatial relationships between trends of the different climate variables under discussion, could be established. The main results, taking all seasons into account, is a general decrease in mean daily low cloud cover, and to a lesser extent total cloud cover, over most of South Africa, but an increase in the south and south-west of the country. However, the sizes of same trend regions show considerable variability between seasons. While trends in DTR and rain days are the opposite and the same, respectively, of trends in cloud cover in most cases, it is shown that this is not always the case. A region covering the northern, central and western interior of South Africa, with late-summer (JFM) cloud cover negatively correlated with equatorial Pacific sea-surface temperatures (SSTs), shows only a non-significant decrease in total and low cloud cover for JFM, which corresponds to a non-significant increase in equatorial Pacific SSTs during the same period.
\end{abstract}

Keywords: cloud cover, climate change, trends, diurnal temperature range, rainfall

\section{Introduction}

In the light of the climate change debate, assessments of historical climate change over regions of which such studies are not published often, such as sub-Saharan Africa in this case, could be regarded as important. The detailed spatial and temporal trends and variability of low and total cloud cover, as well as of related climate variables diurnal temperature range (DTR) and number of rain days, over the period 1960 to 2005, are investigated for South Africa. This is the first study of trends in cloud cover which focuses only on South Africa, and aims to present more detailed results than already published global studies of cloud-cover trends

Varying results for trends in cloud cover for the latter half of the past century were found by various authors, of which some of the most noteworthy regional studies are mentioned: Dai et al. (2006) showed that United States total cloud cover showed an increasing trend from 1976 to 2004. Also for the United States, Groisman et al. (2004) indicated that not only total cloud cover, but also low cloud cover increased during the past 50 years. These increases in cloud cover were found to coincide with increases of other climatic indicators, such as precipitation, evaporation and streamflow, alluding to an intensification of the hydrological cycle. Investigating only 350 station records worldwide, but with records extending over the long period from 1900 to 1985, Henderson-Sellers (1992) found increases in cloud amounts over North America, Europe, India

* To whom all correspondence should be addressed.

前 +27 12367 6074; fax: +27 123676175 ;

e-mail: Andries.Kruger@weathersa.co.za

Received 9 February 2007; accepted in revised form 1 August 2007. and Australia. Sun and Groisman (2000) found that although total cloud cover increased in the former Soviet Union from 1936 to 1990, an opposite tendency was found for low cloud cover, which decreased significantly. From the above-mentioned studies it is clear that historical trends in cloud cover are not uniform for the globe.

The most comprehensive study on trends in cloud cover by Warren et al. (2007), utilising the synoptic data from a total of 5388 climate stations, found an average decrease in global mean cloud cover over land, for the period 1971 to 1996. For Southern Africa this study indicates a decrease in the annual mean of mean daily total cloud cover, but an increase in a $10^{\circ} \times 10^{\circ}$ grid box south-west of the continent which also includes a small part of the south-western Cape. As will be shown, these results are broadly similar to those presented in this paper, although in Warren et al. (2007) no significance is given for the trends established, and also it is not really possible to establish from the results published where in South Africa the borders are between areas of different trends. Warren et al. (2007) aimed to present a general impression of global trends, and therefore in most parts of the paper do not deal with trends in detail for specific regions of the globe. The main objective of this study is that it aims to present a more detailed and updated overview of the changes in cloud cover experienced in South Africa.

Additional to total and low cloud cover, trends of related climate variables, DTR (the difference between the daily maximum and daily minimum temperature), and number of rain days, are also presented. These additional trend calculations, which are associated with trends in cloud cover, can provide an explanation for the differences in historical trends in DTR found among South African climate stations (Kruger and Shongwe, 2003), as the global trend for DTR is to decrease (Easterling et al., 2000). 
For most seasonal time series, cloud cover and DTR are significantly negatively correlated, while cloud cover and number of rain days are significantly positively correlated. Also, decreases (increases) in cloud cover may be related to increases (decreases) in DTR and decreases (increases) in number of rain days. These established relationships provide additional confidence in the data utilised in the study.

Variations in late-summer January to March (JFM) cloud cover can be linked to variations in the El Niño-Southern Oscillation (ENSO), of which the variability can be indicated by variations in equatorial Pacific sea-surface temperatures (SSTs). Warren et al. (2007) found a similar result for Southern Africa, but for mid-summer (DJF). However, it has been shown that for South Africa the association between ENSO and rainfall, and therefore indirectly cloud cover, is most pronounced during JFM (Kruger, 1999). Also investigated is whether trends in JFM cloud cover can be linked to ENSO.

\section{Data}

An original number of 37 climate stations, managed by the South African Weather Service (SAWS), were selected for analyses, which have at least $95 \%$ cloud, precipitation and temperature data available for the period 1960 to 2005 . The steps followed to detect possible inhomogeneities in their data time series, in order to ensure that only climate stations with high-quality data were employed for the study, were the following: At several climate stations discontinuities could be detected in their cloud cover time series, usually indicating a change of observers. Data problems also arose from changes in location over short distances as well as changeovers from conventional to automatic instrumentation, mostly affecting the temperature time series tested. For some climate stations the detected discontinuities could not be effectively removed, resulting in the number of stations utilised in the study to be reduced to an eventual total of 28 . It is recognised that with such a small number of stations covering South Africa, the description of regional trends can be challenging over some areas.

Cloud observations at 08:00, 14:00 and 20:00 South African Standard Time (SAST), were used to calculate daily means. These observation times were selected as 16 of the 28 stations utilised are climate stations manned by voluntary observers that only report observations at the mentioned times, while the data for non-main synoptic times (all hours except 00:00, 08:00, 14:00 and 20:00 SAST) for the remainder of stations have not been digitised. It is debatable whether additional observations included in the averaging procedure would make much difference in the trend results. In a similar study Kaiser (1998) found minimal differences in trends of daytime and night-time cloud cover over China for the period 1951 to 1994

For the entire study period the observation practice of cloud cover has remained consistent with World Meteorological Organisation (WMO) standards. Low cloud cover refers to the portion of the sky in octas covered by clouds with base heights usually below $2500 \mathrm{~m}$, for example Cumulus, Cumulonimbus, Stratus, Stratocumulus, Fractocumulus, Fractostratus and Nimbostratus. Total cloud cover refers to the portion of the sky in eights covered by clouds at any height. A precipitation day is defined as a day when precipitation of $0.2 \mathrm{~mm}$ or more was measured.

Associations between cloud cover and ENSO were done by correlating JFM mean daily cloud cover with JFM SSTs in the NINO3.4 region (a region in the equatorial Pacific Ocean bounded between $5^{\circ} \mathrm{N}$ to $5^{\circ} \mathrm{S}$, and $120^{\circ}$ to $170^{\circ} \mathrm{W}$ ); the data were sourced from the National Oceanic and Atmospheric Administration (NOAA) National Weather Service Climate Prediction Center website (NOAA, 2006).

\section{Methodology}

Analyses were subdivided into seasons as follows; March to May (MAM), June to August (JJA), September to November (SON) and December to February (DJF). Because isolated extreme values were non-existent in the time series, due to averaging of daily means over seasons, linear trends of time series could be calculated with least-squares regression. The correlation coefficient of both the trends of time series and linear relationships between climate variables were tested for significance by the two-sided $t$-test at the $5 \%$ level:

$$
r=\frac{t}{\sqrt{n-2+t^{2}}}
$$

where:

$r$ is the test statistic

$n$ is the length of the time series/pairs of observation

$t$ is the critical value obtained from the t-distribution, corresponding to the $5 \%$ significance level $(\alpha=0.025)$ and $n-2$ degrees of freedom

Regionally averaged series were determined only for areas with stations showing similar trends, and were delineated in such a way that the trend of the averaged series of stations within the regions, depicted in Figs. 1 to 4, would be statistically significant. The methodology employed to calculate the averaged series is the same as that by New et al. (2006):

$$
x_{r, t}=\frac{1}{n_{t}} \sum_{i=1}^{n_{t}}\left(\frac{x_{i, t}-\bar{x}_{i}}{s_{i}}\right)
$$

where:

$x_{r, t}$ is the regionally averaged series value at year $\mathrm{t}$

$x_{i, t}$ is the series value for station $\mathrm{i}$ at year $\mathrm{t}$

$\bar{x}_{i}$, is the series mean at station $i$ over the period 1960 to 2005

$s_{i}$ is the standard deviation of series values at station i over the period 1960 to 2005

$n_{t}$ is the number of stations with series values in year $\mathrm{t}$

Because the spatial coverage of useful climate stations is not ideal, it must be noted that the areas delineated in the results do not necessarily give a totally true reflection of the extent of areas of similar trend, but attempt to indicate the variability of sametrend regions between seasons, as well as the apparent spatial relationships between trends of the different climate variables under investigation.

\section{Results}

\section{Relationships between cloud cover, DTR and number of rain days}

Clouds, especially those with low bases, reduce the diurnal temperature range by shielding off solar radiation in daytime causing lower maximum temperatures, and reradiating long-wave terrestrial radiation during night-time, avoiding the steep decline in surface temperature usually experienced during clear skies in the early morning. Also, an increase in cloud cover, especially if it is low, will usually cause an increase in the number of rain days and vice versa. Therefore, reliable cloud observation values should usually have a negative relationship with DTR, and 
a positive relationship with the number of rain days (Dai et al., 1997; Dai et al., 1999; Rebetez and Beniston, 1998). Table 1 indicates that for all seasons detrended seasonal time series for the majority of climate stations show significant linear correlations between mean daily cloud amounts and mean DTR, and mean daily cloud amounts and total number of rain days. These significant correlations provide additional confidence in the data utilised in the study.

\section{Trend in cloud cover}

Figures 1 and 2 show the trends for MAM, JJA, SON and DJF, for daily mean total cloud amount and daily mean low cloud amount. Climate stations in the delineated areas on the maps have similar trends with averaged series that tested positive for statistical significance. One can conclude that there is, in general, a tendency toward increased cloud cover in the south and south-west, and a tendency towards decreased cloud cover northwards over most of the remainder of South Africa, similar to the findings of Warren et al. (2007). The depicted areas with significant regionally averaged trends do not remain static between seasons.

The area in the south of the country in Fig. 1, which shows a significant positive trend in total cloud amount, reaches its maximum size in SON and DJF when it covers almost the entire south-western and southern Cape, while in MAM and JJA only a few stations show significant positive trends. The opposite is true for the area towards the north with significant negative trends in total cloud cover. It reaches its maximum size

\section{Figure 1 (top right)}

Trends in octas per decade for daily mean total cloud cover per season. Areas with significant mean trends are indicated.

Figure 2 (bottom right)

Trends in octas per decade for daily mean low cloud cover per season. Areas with significant mean trends are indicated.
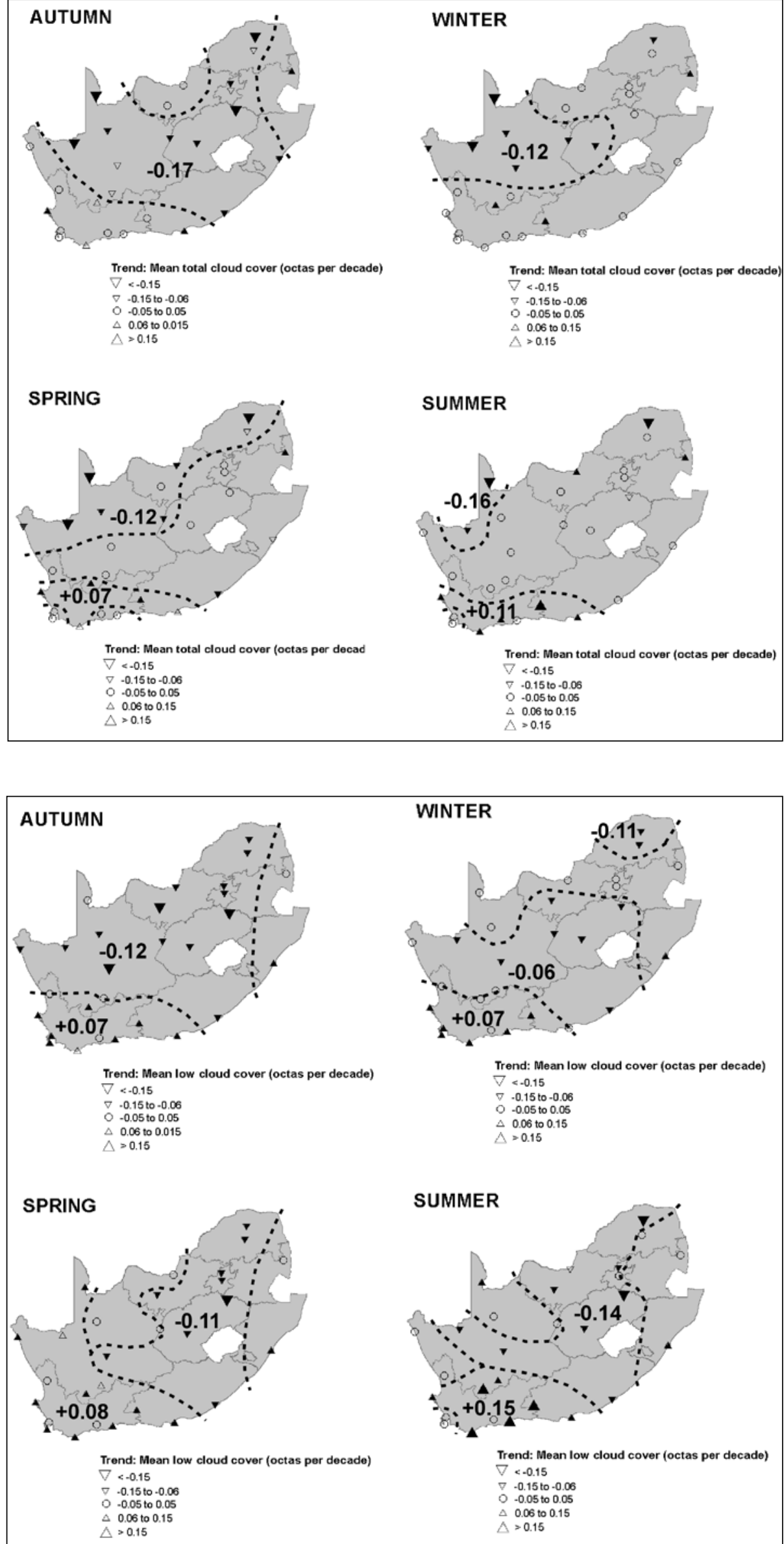
TABLE 1

Percentage of stations with significant linear correlations between indicated climatic variables at the $5 \%$ level

\begin{tabular}{|c|c|c|c|c|}
\hline \multirow[t]{2}{*}{ Climate variables } & \multicolumn{4}{|c|}{ Season } \\
\hline & MAM & JJA & SON & DJF \\
\hline Mean daily total cloud amount and DTR (negatively correlated) & $96.6 \%$ & $86.2 \%$ & $89.7 \%$ & $89.7 \%$ \\
\hline Mean daily low cloud amount and DTR (negatively correlated) & $96.6 \%$ & $82.8 \%$ & $75.9 \%$ & $89.7 \%$ \\
\hline Mean daily total cloud amount and total number of rain days (positively correlated) & $93.1 \%$ & $86.2 \%$ & $93.1 \%$ & $93.1 \%$ \\
\hline Mean daily low cloud amount and total number of rain days (positively correlated) & $89.7 \%$ & $89.7 \%$ & $89.7 \%$ & $79.3 \%$ \\
\hline
\end{tabular}

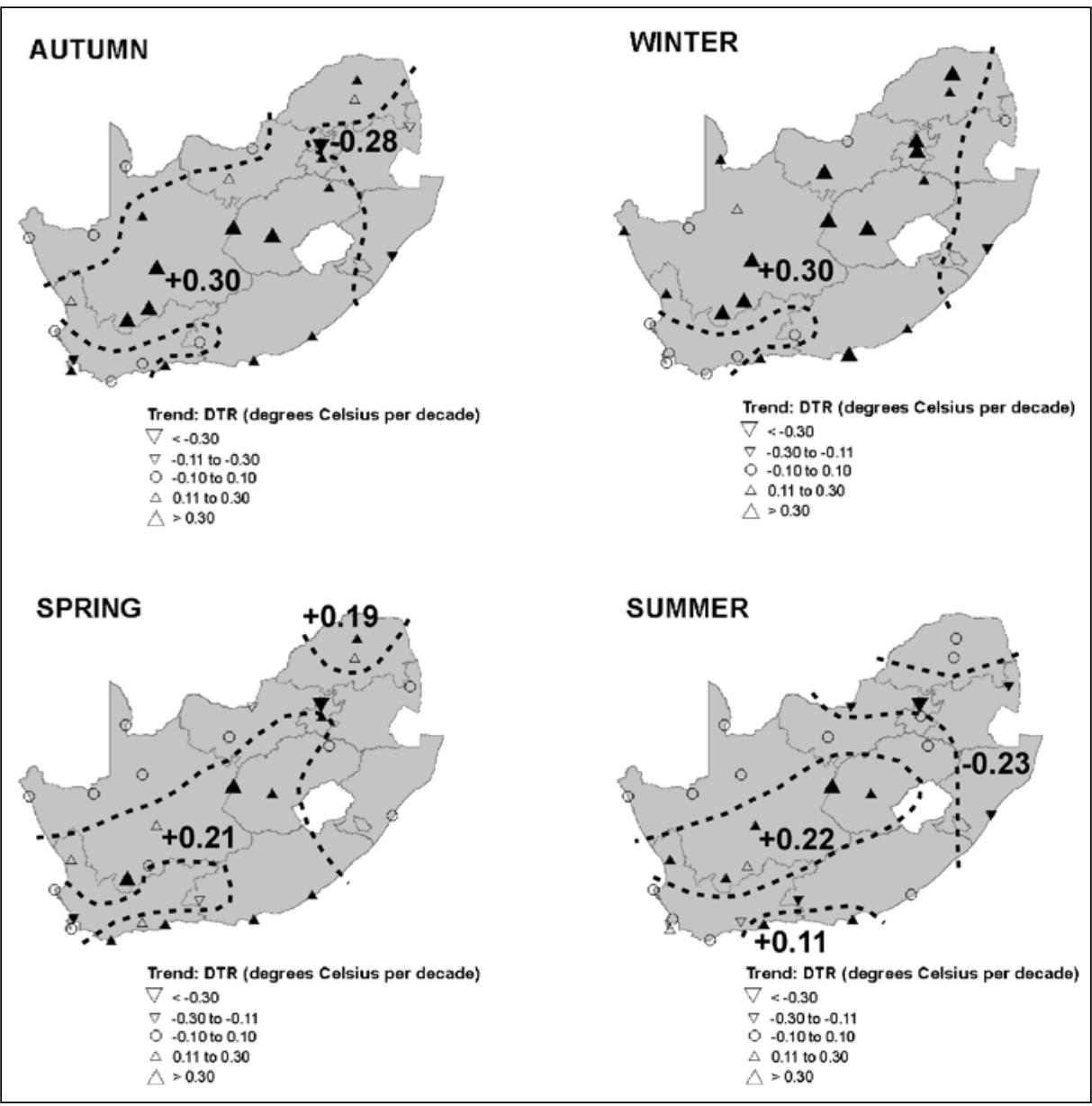

Figure 3

Trends in degrees Celsius per decade for daily mean seasonal DTR. Areas with significant mean trends are indicated

during MAM and JJA, while in DJF only two stations in the extreme western interior shows significantly negative trends in total cloud cover.

Trends in low cloud cover, as shown in Fig. 2, show better spatial consistency between seasons than in the case of total cloud cover. However, the area with a significant increase in low cloud cover in the south is still largest in SON and smallest in JJA. The area of significant decrease of low cloud cover is much larger for all seasons when compared to total cloud cover. In MAM and JJA it covers more or less the whole of South Africa, but excluding the areas in the south which experienced increased cloud cover, as well as the extreme eastern parts. Therefore, consistent with the results for total cloud cover, the maximum spatial extent for decreased low cloud cover occurs during MAM and JJA, and the minimum extent in SON and DJF.

\section{Trend in DTR}

As previously discussed, areas with increased (decreased) cloud cover should show a decrease (increase) in DTR. For the vast majority of climate stations utilised in this study there are significant linear correlations between cloud cover and DTR. Therefore, it can be expected that if there are areas with significant trends in cloud cover, essentially the same areas should show significant trends in DTR but of the opposite sign. For the southern and south-western Cape, however, where for all seasons an area of significant increase in cloud cover could be identified, an area with decreased DTR could not be identified, as can be seen in Fig. 3. However, an exception is Cape Town which shows a significant decrease in DTR for SON and MAM. For all seasons, but especially in JJA, a large part of South Africa shows increased DTR. These seasonal areas show consistency with areas of decreased cloud cover in Figs. 1 and 2; therefore the decrease in mean daily cloud amount most probably plays a major role in the increase in DTR.

The global tendency was for DTR to decrease during the period 1950 to 2004, but from 1979 to 2004 DTR trends were muted, as increases in minimum and maximum temperatures became more comparable. Trends also differed widely in regional bases (Vose et al., 2005). In a study on temperature trends in South Africa, Kruger and Shongwe (2004) found that tendencies in DTR were not spatially consistent throughout South Africa, and no explanation for increased DTR could be offered then.

\section{Trend in number of rain days}

Figure 4 shows the seasonal tendencies in the number of rain days, and a causal relationship between increased (decreased) cloud cover and increased (decreased) number of rain days can be inferred, especially in the case of low cloud cover, from which rain is possible. For MAM one can see that there is a resemblance between the areas of decreased low cloud cover and decreased 
number of rain days, the only noteworthy exception being the southern Cape. Almost the same is true for JJA, but the area of decreased number of rain days does not extend to the north-east, possibly because it is an area that receives minimal rainfall during JJA. For SON and DJF there are only three climate stations for each season that show any significant trend, while extensive areas show significant changes in low cloud cover for both seasons.

\section{Correlation between ENSO and cloud cover}

The ENSO phenomenon, which presents itself as El Niño (La Niña) conditions in the equatorial Pacific Ocean, is associated with low (high) rainfall during the austral summer for most of the summer rainfall region of South Africa. However, the effect of ENSO on South African rainfall is most pronounced during JFM (Kruger, 1999). As there is a logical link between cloud cover and rainfall, it is investigated whether this link can be confirmed from the data. From Fig. 5 ( $a$ and b) it is evident that for most climate stations in the interior JFM mean daily total and low cloud cover is significantly negatively correlated with mean JFM SST anomalies in the NINO3.4 region of the equatorial Pacific Ocean. The time series of standardised anomalies of the mean total and low cloud cover for these climate stations, together with JFM mean NINO3.4 SST anomalies, are presented in Fig. 5(c). The climate stations with cloud cover significantly negatively correlated with NINO3.4 SSTs show, on average, only a slight non-significant decrease in mean daily total and low cloud cover in JFM, which corresponds with the non-significant increase in NINO3.4 SSTs from 1960 to 2005. It is therefore evident that there is a significant correlation between ENSO and JFM cloud cover over most of the interior of South Africa, but that ENSO does not play a meaningful role in the decrease in cloud cover experienced.

\section{Conclusions}

Reliable cloud observation values should usually have a significant negative relationship with DTR, and a significant positive relationship with the number of rain days. For most cases, daily mean seasonal cloud amounts are significantly negatively correlated with
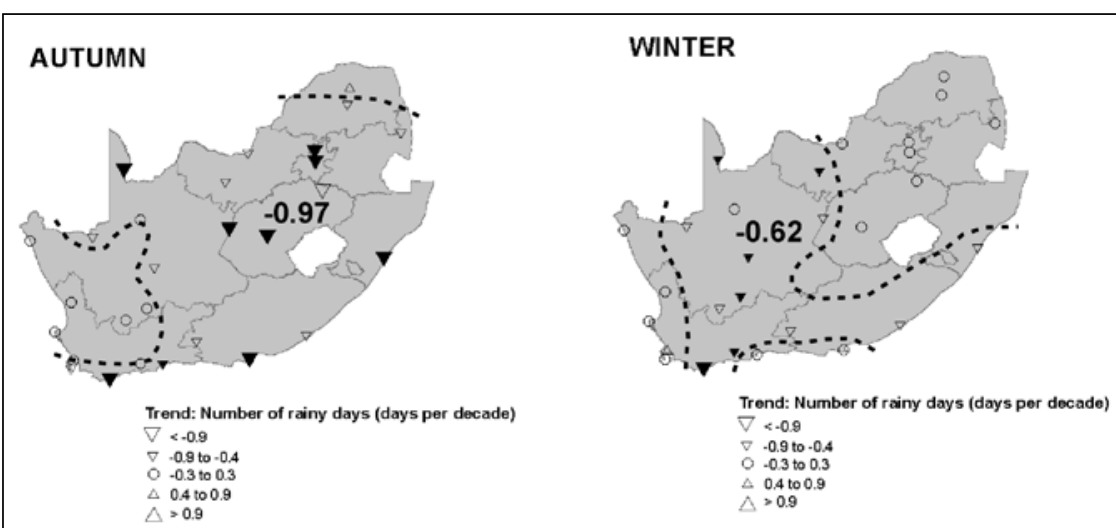

SPRING
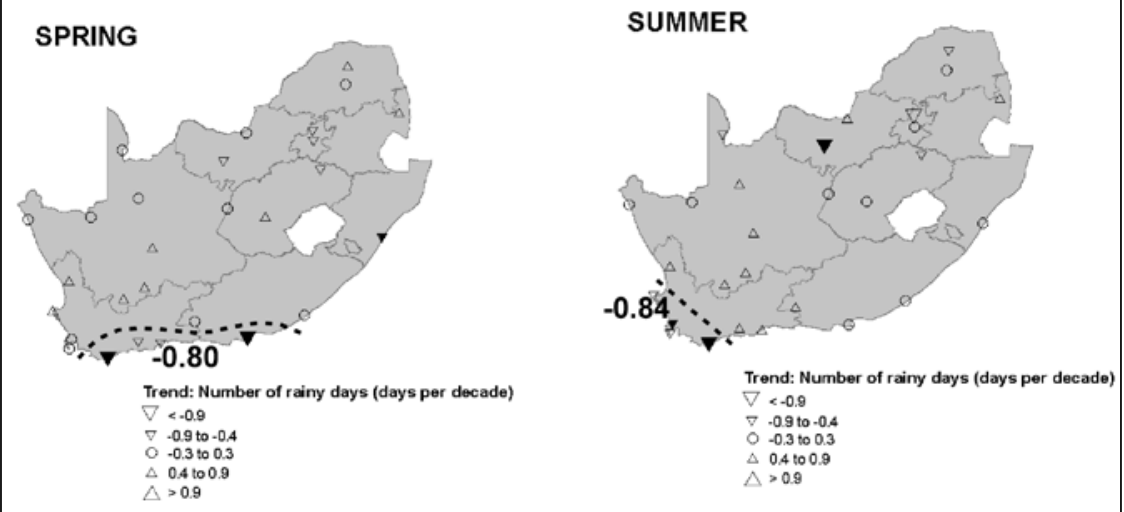

Figure 4

Trends in days per decade for total seasonal number of rain days (rainfall greater than $0.2 \mathrm{~mm}$ ). Areas with significant mean trends are indicated.

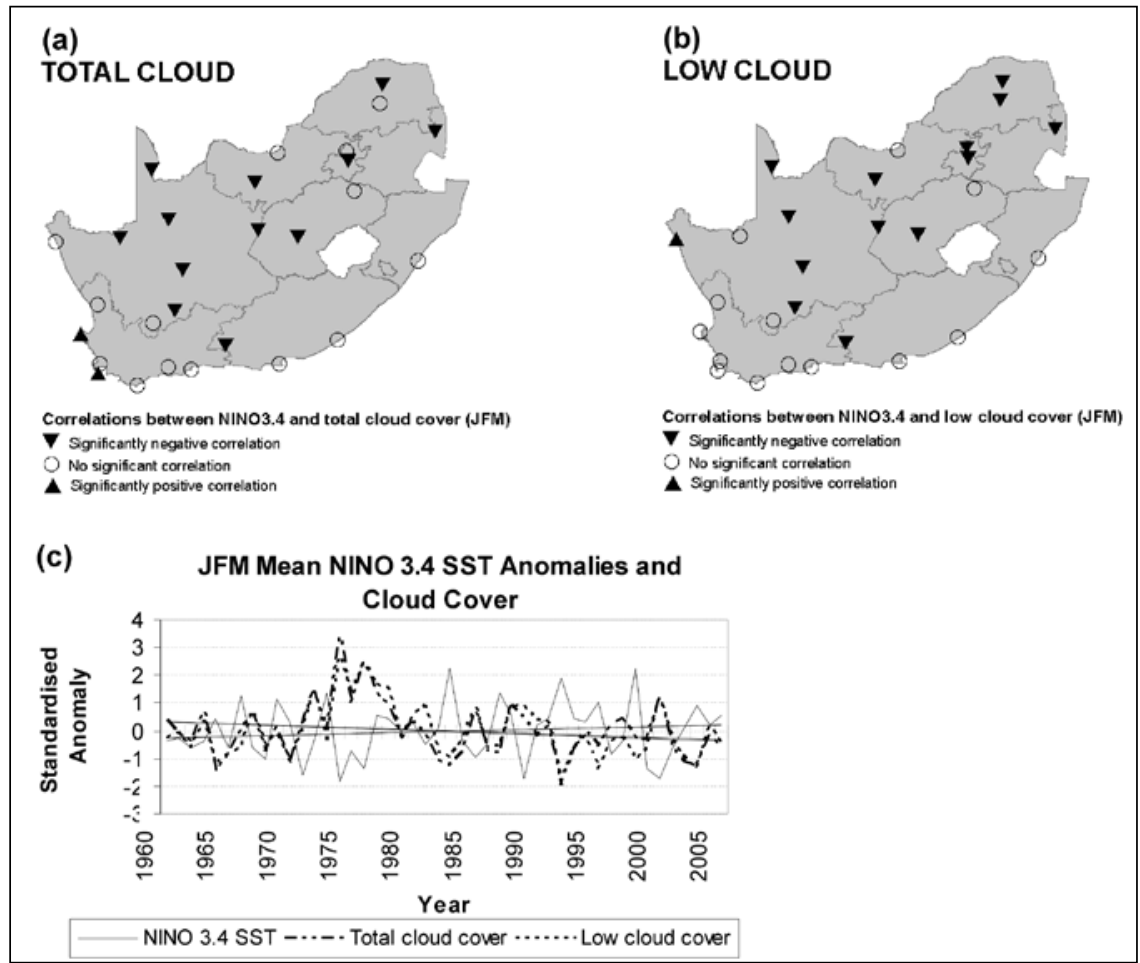

Figure 5

Correlations between JFM mean NINO3.4 SSTs and (a) daily mean total cloud cover, and (b) daily mean low cloud cover. In (c) the standardised time series of JFM mean NINO3.4 SSTs are shown; together with time series of standardised anomalies of mean total and low cloud cover for stations in (a) and (b) showing significantly negative correlations. Linear trend lines are depicted as solid lines. 
seasonal mean DTR, and significantly positively correlated with seasonal number of rain days, providing additional confidence in the data utilised in the study.

Mean daily amounts of both total and low cloud cover have changed significantly over most areas of South Africa. These changes are different between seasons, with trends stronger and more widespread for low clouds than for total cloud amounts. In general one can say that over the past 46 years there has been a decrease in mean daily total and low cloud cover over most of the interior, but an increase in the south and south-west. It is, however, evident that the maximum spatial extent for decreased cloud cover occurs during MAM and JJA, and minimum extent in SON and DJF. In the south and south-west the spatial extent of increased cloud cover is largest in SON and smallest in JJA.

It has been shown that there are large overlaps between regions with increased (decreased) cloud cover, decreased (increased) DTR and increased (decreased) number of rain days. However, these relationships between cloud cover, DTR and number of rain days are not always true for all climate stations, and therefore further research is proposed to identify other factors which play a role.

The ENSO phenomenon is significantly correlated with JFM cloud cover over a large part of the summer rainfall region, but does not seem to play a significant role in the trends in cloud cover observed during that time of year, when a significant amount of climate stations showed a decrease in low cloud cover. With ENSO most probably not a factor in the trends in cloud cover observed, there should be another reason why mean seasonal cloud cover amounts did not remain constant during the study period. While identifying the factors causing the trends in cloud cover observed is not the main scope of this paper, it is recommended that a follow-up study should attempt to identify the causes of the trends observed.

The data analysis carried out in this investigation provide updated and more spatially and temporally detailed results for South Africa than those provided in a previous study by Warren et al. (2007), which aimed to give a more global overview of observed trends in cloud cover

\section{References}

DAI A, DEL GENIO AD and FUNG IY (1997) Clouds, precipitation and temperature range. Nature 386 665-666.
DAI A, KARL TR, SUN BE and TRENBERTH KE (2006) Recent trends in cloudiness over the United States: A tale of monitoring inadequacies. Bull. Amer. Meteor. Soc. 87 597-606.

DAI A, TRENBERTH KE and KARL TR (1999) Effects of clouds, soil moisture, precipitation, and water vapor on diurnal temperature range. J. Climate 12 2451-2473.

EASTERLING DR, KARL TR, GALLO KP, ROBINSON DA, TRENBERTH KE and DAI A (2000) Observed climate variability and change of relevance to the biosphere. J. Geophys. Res. 105 2010120114.

GROISMAN PY, KNIGHT RW, KARL TR, EASTERLING DR, SUN B and LAWRIMORE JH (2004) Contemporary changes of the hydrological cycle over the contiguous United States: Trends derived from in situ observations. J. Hydromet. 5 64-85.

HENDERSON-SELLERS A (1991) Continental cloudiness changes this century. Geo J. 37 255-262.

KAISER D P (1998) Analysis of total cloud amount over China, 19511994. Geophys. Res. Lett. 25 (19) 3599-3602.

KRUGER AC (1999) The relationship between the decadal-scale variability of summer rainfall on the impact of El Niño and La Niña events in South Africa. Int. J. Climatol. 19 59-68.

KRUGER AC and SHONGWE S (2004) Temperature trends in South Africa: 1960-2004. Int. J. Climatol. 24 1929-1945.

NEW M, HEWITSON B, STEPENSON DB, TSIGA A, KRUGER A, MANHIQUE A, GOMEZ B, COELHO CAS, MASISI DN, KULULANGA E, MBAMBALALA E, ADESINA F, SALEH H, KANYANGA J, ADOSI J, BULANE L, FORTUNATA L, MDOKA ML and LAJOIE R (2006) Evidence of trends in daily climate extremes over Southern and West Africa. J. Geophys. Res. 111 (D14102) DOI: 10.1029/2005JD006289

NOAA (2006) National Weather Service. Climate Prediction Center. Cold and Warm Episodes by Season (2006). http://www.cpc.ncep. noaa.gov/products/analysis monitoring/ensostuff/ensoyears.shtml Accessed on 7 Dec 2006.

REBETEZ M and BENISTON M (1998) Changes in sunshine duration are correlated with changes in daily temperature range this century: An analysis of Swiss climatological data. Geophys. Res. Lett. 25 (19) 3611-3613.

SUN B and GROISMAN PY (2000) Cloudiness variations over the former Soviet Union. Int. J. Climatol. 20 1097-1111.

VOSE RS, EASTERLING DR and GLEASON B (2005) Maximum and minimum temperature trends for the globe: An update through 2004. Geophys. Res. Lett. 32 (L23822) DOI: 10.1029/2005GL024379.

WARREN SG, EASTMAN RM and HAHN CJ (2007) A survey of changes in cloud cover and cloud types over land from surface observations, 1971-1996. J. Clim. 20 717-738. 